\title{
La política de la diferencia: estatalidad y tolerancia en un mundo multicultural *
}

\author{
MICHAEL WALZER \\ Institute for Advanced Study, Princeton
}

En este trabajo se analiza el problema de la tolerancia desde el punto de vista internacional. Este cambio de enfoque respecto del que es tradicional permite descubrir algunos elementos interesantes. Por ejemplo, que los imperios resultan más tolerantes con la diferencia que los Estados-nación, que el consociacionalismo, siendo el arreglo institucional acaso más equitativo para comunidades diferentes es, por ello mismo, el más improbable, etc. El multiculturalismo, el respeto a la diferencia, la individualidad posmoderna y otros temas centrales a la teoría política contemporánea se relacionan aquí también con la tolerancia y sus paradojas.

Como buen profesor, quisiera comenzar con algunas distinciones. En este artículo no voy a centrarme (excepto al final) en la tolerancia que se ejerce respecto de individuos excéntricos o disidentes en el scno de la socicdad civil $o$, incluso, en el ámbito estatal. Es posible que en la base de toda tolerancia se hallen los derechos individuales, pero, en principio, estos últimos me resultan de interés tan sólo en la medida en que se ejercen en común (en el ámbito de asociaciones voluntarias, en el seno del culto religioso, como forma de expresión cultural), o bien cuando son reclamados por los grupos en favor de sus miembros. El individuo excéntrico, solitario en su diferencia, es más fácilmente tolerable, a la par que la repugnancia social y las formas de resistencia frente a esa excentricidad si bien, ciertamente, pueden resultar poco atractivas no suponen un terrible peligro. Lo que está en juego, sin embargo, es mucho más importante si lo que tomamos en consideración son grupos excéntricos $o$ disidentes.

Tampoco me voy a centrar en la tolerancia política, en la cual los grupos en cuestión son movimientos o partidos que entran en un juego agonal y conflictivo. En este caso, nos hallamos ante competidores por el poder político, cuya existencia es necesaria en los regímenes democráticos, en los cuales se requiere, literalmente, que haya líderes alternativos (con programas alterna-

* Traducción de Rafael del Águila. 
tivos), incluso aunque algunos de ellos nunca lleguen a ganar unas elecciones. Por lo tanto, se trata de compañeros, de participantes, algo similar a los jugadores del equipo contrario en un partido de baloncesto, sin los cuales simplemente no habría juego, y que, por tanto, si pueden, tienen derecho a encestar y ganar. Tan sólo surgen problemas en el caso de que aparezcan personas que desean interrumpir el juego, a la par que siguen reivindicando que se les apliquen los derechos de los jugadores y que se respetcn, también en su caso, las reglas por las que se rige el juego. Este tipo de problemas resultan a menudo espinosos, pero no tienen mucho que ver con la tolerancia de lo diferente (algo intrínseco a toda política democrática), sino que más bien se hallan relacionados con la tolerancia de la ruptura o del riesgo de que se genere esa ruptura, lo cual es un problema totalmente distinto.

De lo que quiero tratar aquí es de la tolerancia cuando lo que está en juego son diferencias culturales, religiosas, diferencias que afectan al modo de vida en aquellos casos en que los demás no son compañeros de juego, cuando de hecho no existe un juego común y, por lo tanto, la diferencia no es una necesidad intrínseca. Ni siquiera una sociedad liberal requiere de una multiplicidad de grupos étnicos o de comunidades religiosas $\mathrm{y}$, por supuesto, ninguna de estas agrupaciones prccisa de la existencia de los demás, ni tan siquiera de la de algunos de ellos. A menudo estos grupos entrarán en competencia unos con otros, buscando conversos o adeptos entre individuos no comprometidos o, en todo caso, débilmente comprometidos. Sin embargo, su objetivo primordial es el de garantizar, para sus miembros, el mantenimiento de una determinada forma de vida, el poder de reproducir su cultura o su fe entre las generaciones futuras. Por tanto, su máxima prioridad es centrarse en lo interno, algo que los partidos políticos no pueden hacer. Al mismo tiempo reivindican algún tipo de espacio social (al margen del ámbito estrictamente interno) para poder reunirse, celebrar el culto, organizar discusiones públicas, celebraciones, sistemas de ayuda mutua o para influir sobre el sistema educativo de sus hijos, etc.

Ahora bien, ¿qué significa tolerar la existencia de este tipo de grupos? Descrita bien como una actitud, bien como un estado mental (del que derivan ciertas prácticas características), la tolerancia puede ser entendida de diversas formas. En primer lugar hay que considerar, de entre las descripciones posibles, aquella en la que se reflejan los orígenes de la tolerancia religiosa de los siglos xvi y XVI. En este caso se trataría de la aceptación resignada de la diferencia, en aras de la paz. Las personas se matan unas a otras durante años y años hasta que un buen día quedan exhaustas y a esto llamamos tolerancia. Sin embargo, también se puede hallar toda una serie de acepciones más sustantivas que formarían una especie de continutu. Existe un segundo tipo posible de actitud que resulta ser pasiva, relajada, benignamente indiferente: stiene que haber de todo». En tercer lugar, se puede hablar de tolerancia para expresar una cierta condición de apertura hacia los demás, de 
curiosidad, de respeto y de deseo de escuchar y aprender. $\mathrm{Y}$ en el extremo más alejado del continuum se hallaría el apoyo entusiasta a la diferencia: un apoyo de carácter estético cuando se considera que la diferencia encarna, de una manera cultural, la inmensidad y diversidad de la creación divina o del mundo de la naturaleza; o bien un apoyo de tipo funcional, siempre que se entienda que la diferencia es una condición esencial para permitir el desarrollo humano, puesto que proporciona a los individuos, hombres y mujeres, la posibilidad de efectuar el tipo de elecciones que dan sentido a su autonomía.

Pero, quizás, esta última acepción quede fuera de mi ámbito de estudio, ya que ¿cómo puedo decir que tolero lo que de hecho apoyo? Si deseo que los «otros» se hallen aquí, en esta sociedad, entre nosotros, no estoy tolerando la diferencia, la estoy promoviendo. Empero, ello no implica que necesariamente deba conceder mi apoyo a esta o aquella versión de lo diferente. Podría preferir otra distinta, cultural o religiosamente más ligada a mis propias prácticas o creencias (o tal vez más alcjada de cllas, más exótica, que no pueda suponer amenaza competitiva alguna). Por lo tanto, parece posible afirmar que, incluso si promuevo la idea de diferencia, tolero de hecho diferencias concretas. Además, en cualquier sociedad democrática, por muy arraigado que se encuentre el compromiso de respetar el pluralismo, siempre habrá personas a las que resulte verdaderamente difícil tolerar; algún tipo de diferencia concreta (diferencias de culto, distintos modos de entender la familia, normas sobre dietética o formas de vestir). Diré, sin embargo, que todas aquellas personas que realmente aceptan diferencias de este tipo poseen, independientemente del lugar en el que se sitúen en ese continuum de resignación, indiferencia, curiosidad 0 entusiasmo, la virtud de ser tolerantes.

Asimismo, me gustaría aludir a los acuerdos sociales a través de los cuales incorporamos lo diferente, coexistimos con ello, le concedemos un espacio social propio, ya que se trata de formas institucionalizadas de esta misma virtud. Históricamente se han dado cuatro tipos diferentes de compromisos, alcanzados en pro de la tolerancia; en definitiva, cuatro modelos de sociedades tolerantes. Quisiera describirlos brevemente y de forma esquemática para, postcriormente, decir algo sobre el grado de la autocomprensión ejercida por los hombres y mujeres que mantienen vivos estos pactos hoy en día (en la medida en que sigan resultando eficaces: la tolerancia siempre es un logro precario) ¿Quć hacemos exactamente cuando toleramos lo diferente?

En relación a lo que aquí nos ocupa, bien se puede decir que los más antiguos intentos de solución de este tipo de fenómenos provienen de los grandes imperios multinacionales: Persia y Roma. En estos casos, los distintos grupos se constituyen en comunidades autónomas de carácter político-legal, y también 
cultural-religioso, que se caracterizarian por el ejercicio efectivo del autogobierno en relación con un amplio espectro de actividades. Estos grupos no tienen elección, deben coexistir unos con otros, ya que la forma en que se llevan a cabo las interacciones que se puedan dar entre ellos es determinada por los burócratas imperiales, según lo especificado en un código imperial pensado, como el ius gentium romano, para garantizar una mínima equidad, tal y como ésta es entendida en el núcleo del imperio. Sin embargo, por lo general, los burócratas no interficren en los asuntos internos de las comunidades autónomas, ni en aras de la equidad ni por ningun otro motivo - siempre que se paguen los impuestos y se mantenga el orden-. Se puede afirmar, por tanto, que se toleran distintos modos de vida y así el régimen imperial puede calificarse de tolcrante, al margen de que las distintas comunidades sean o no tolerantes unas con otras. Bajo la autoridad imperial, lo quicran o no, deben mostrar tolerancia en las relaciones cotidianas y así, quizás, algunos aprendan a aceptar lo diferente situándose en algún lugar del continuum que he descrito anteriormente. Pero la superviviencia de las distintas comunidades no depende de esta aceptación. Tan sólo depende de la tolerancia burocrática, que se mantiene, básicamente, en aras de la paz (si bien burócratas individuales pueden tener otras motivaciones; algunos de ellos resultan célebres por su curiosidad o incluso por su defensa entusiasta de lo diferente).

Probablemente ésta sea la forma más exitosa de incorporar la diferencia y facilitar (tal vez fuera más exacto decir exigir) la coexistencia pacífica. Pero no es, o al menos nunca. lo ha sido, un modo democrático de hacerlo. Sea cual fuere la índole de las diferentes «autonomías», el régimen aglutinador es autocrático. No quiero idealizar esta autocracia; como la historia de Asiria, Israel, Roma, Cartago, España, el Imperio azteca, el ruso o el de los tártaros demuestran ampliamente, estos regímenes pueden ser brutalmente represivos para mantener sus conquistas. Sin embargo, una vez afianzada, la autoridad imperial es a menudo tolerante - tolerante, precisamente porque es autocrática en todo lugar, que es lo mismo que decir que no se ve obligada a considerar los intereses o prejuicios de ninguno de los grupos conquistados-. Ocupa un lugar equidistante en relación con todos ellos. Los procónsules romanos de Egipto o los regentes británicos de la India gobernaban de forma más imparcial de lo que probablemente lo haria cualquier príncipe o tirano local.

La autonomia imperial tiende a encerrar a los individuos en sus comunidades, a mantenerles en el ámbito de una única identidad étnica o religiosa. La tolerancia se ejerce, por tanto, respecto de grupos, sus estructuras de autoridad y sus costumbres y no (excepto en algunas capitales y centros cosmopolitas) respecto de hombres y mujeres individuales, sin nexos de unión entre sí. Los disidentes solitarios o herejes, los vagabundos culturales o las parejas mixtas y sus hijos probablemente huyan hacia la capital del imperio, la cual, como resultado de este proceso, probablemente se convierta en un lugar muy tolerante (piénsese en Roma, Bagdad o Viena); de hecho en el único lugar donde el 
espacio social se intenta redistribuir atendiendo a los individuos. Los demás vivirán en barrios o distritos bastante homogéncos donde su modo de vida será tolerado; sin embargo, no es probable que sean bienvenidos o que puedan circular con seguridad una vez traspasadas las fronteras que les separan de los otros. Tan sólo podrán entablar con ellos contactos relajados en ciertos espacios considerados como neutrales: por ejemplo, el mercado o bien los tribunales y prisiones imperiales. No obstante, la mayor parte del tiempo convivirán pacíficamente unos junto a otros, respetando tanto los límites culturales como los territoriales.

Actualmente ya no existe nada de esto (la Unión Soviética fue el último de los imperios): no hay instituciones autónomas, ni fronteras cuidadosamente delimitadas, ni tarjetas de identidad basadas en adscripciones de carácter étnico, ni siquiera burocracias de largo alcance. Después de todo, la autonomía no significaba gran cosa (lo cual puede ser, quizás, una de las razones que generaron el declive de los imperios). Además, su radio de acción se había visto notablemente reducido a causa del impacto que habían causado ideas modernas ligadas al concepto de soberanía o algunas ideologías totalizadoras incompatibles con todo intento de conjugar lo diferente. Pcro las diferencias étnicas y religiosas sobrevivieron, y allí donde el elemento territorial tenía alguna importancia, las instancias locales (más o menos representativas) retuvicron determinadas funciones mínimas y algún tipo de autoridad simbólica. Caídos los imperios y guiadas por ideologías nacionalistas, estas instancias fueron capaces de reconvertirse rápidamente en algo parecido a la maquinaria estatal, a través de la cual pudieron hacerse con el poder soberano. La soberanía comporta, ciertamente, la inclusión como miembro en el seno de la sociedad internacional, probablemente la más tolerante de todas las sociedades, pero a la que hasta muy recientemente no resultaba sencillo acceder. No voy a dedicar mucho espacio a la sociedad internacional en este artículo, pero sí es importante ser conscientes de que es en su seno donde la mayoría de los grupos preferirían ser tolerados: como Estados-nación (o repúblicas religiosas) con gobiernos, cjércitos y fronteras; coexistiendo con otros Estados-nación en el ámbito del respeto mutuo o, al menos, bajo la égida de un conjunto de normas comunes (aunque su cumplimiento rara vez se imponga).

Antes de entrar a considerar el Estado-nación como un posible ejemplo de sociedad tolerante, desearía mencionar brevemente la existencia de entidades que moralmente - aunque no políticamente- podrian ser asimismo consideradas herederas de los imperios multinacionales: me refiero al Estado consociacional o bi- e incluso trinacional. Partiendo de ejemplos como Bélgica, Suiza, Chipre, Libano o (la nonnata) Bosnia, podría sugerirse la existencia 
de otro espectro de posibilidades a la par que se pone de manifiesto la inminencia del desastre. El consociacionalismo es un programa heroico, puesto que pretende mantener la coexistencia imperial sin la ayuda de los burócratas del imperio y sin que exista la distancia que convertía a esos burócratas en gobernantes más o menos imparciales. De hecho, los diferentes grupos no son tolerados por un único poder trascendente; deben tolerarse unos a otros y elaborar juntos los términos en los que se debe llevar a cabo su coexistencia.

No es que esto sea imposible. Existen mayores probabilidades de éxito allí donde sólo haya dos grupos que se encuentren en mínimas condiciones de igualdad, bien por su número, bien por sus posibilidades de ejercer el poder político. Esta igualdad debe, además, poderse mantener a través del tiempo. En este supuesto, la distribución porporcional de recursos y cargos públicos resulta relativamente sencilla y ninguno de los grupos debe temer una posible dominación por parte del otro. Cada uno de cllos mantiene sin interferencia sus propias costumbres e incluso es posible que se refuercen las normas consuetudinarias. Lo que destruye el sistema consociacional es el miedo a las interferencias, el temor a la dominación ejercida por el otro grupo. La tolerancia mutua depende de la confianza, basada no tanto en la buena voluntad del «otro» como en la existencia de acuerdos institucionales que puedan preservar de los efectos de la mala voluntad. No puedo vivir de forma tolerante junto a alguien que considero peligroso ¿Qué es lo que temo? Que, a la postre, el sistema consociacional acabará colapsándose, dando paso al surgimiento de un Estado-nación ordinario, en el seno del cual tan sólo seré miembro de una minoría, tratando de ser tolerado por mis antiguos socios que, de hecho, ya no precisan de mi propia tolerancia hacia ellos.

\section{IV}

La mayor parte de los Estados que conforman la sociedad internacional son Estados-nación. Esta denominación no implica que cuenten con poblaciones nacionalmente (o bien étnica o religiosamente) homogéneas. En el mundo actual, la homogencidad es algo raro, por no decir inexistente. Tan sólo supone que un único grupo dominante organiza la vida en común de modo que queden reflejadas su propia historia y cultura y que, si todo va bien, sea ese mismo grupo el que siga conformando la historia y manteniendo viva la cultura. Estas pretensiones son las que determinan las características propias de la educación pública, los símbolos que se han de utilizar y las ceremonias que se han de celebrar públicamente, el calendario estatal y las festividades que en él se incluyen. Por lo tanto, a lo largo de la historia y respecto de las diversas culturas el Estado-nación no es algo neutro; el aparato del Estado es un motor pensado para la reproducción nacional. No obstante, en su seno se puede tolerar la existencia de minorías, como de hecho ocurre con cierta frecuencia 
en el ámbito de los Estados-nación liberales y democráticos. Esta tolerancia se puede estructurar de muy diversas formas, si bicn rara vez se alcanza el tipo de autonomía completa que se daba en los imperios antiguos. Resulta especialmente improbable que se admita la autonomía regional, ya que los miembros de la nación dominante que residieran en una región determinada se sentirían sometidos a un gobierno «extranjero» en su propio país.

Así pues, por lo general, la tolerancia en los Estados-nación no se ejerce respecto de grupos, sino de los miembros de esos grupos, minorías sobre las que normalmente se manejan estereotipos y a las que se permite (de hecho se espera que deseen) formar asociaciones voluntarias, crear organizaciones de ayuda mutua, escuelas privadas, sociedades culturales, editoriales, etc. No están autorizadas, sin embargo, a llevar una existencia corporativa, ni ostentan jurisdicción legal alguna respecto de sus miembros. Religión, cultura o historia minoritarias entran en el ámbito de lo que podría denominarse lo «colectivo-privado», respecto de lo cual lo «colectivo-público», cl Estado-nación, siempre mucstra reticencias. Cualquier pretensión de comportarse en público de acuerdo con alguna cultura minoritaria suele producir ansiedad entre las mayorías (piénsese en la controversia suscitada en Francia respecto de la admisibilidad de acudir a los colegios estatales utilizando el velo musulmán). En principio, no se coacciona a los individuos, pero hasta muy recientemente se ejercía (de modo general y con bastante éxito) una cierta presión para lograr que las minorías fueran asimiladas en la nación dominante, al menos en lo que respecta a las prácticas públicas. Cuando en el siglo xix los judios alemanes se describían a sí mismos como alemanes en la calle y judíos en su casa aspiraban, de hecho, a la obtención de una norma, emanada del Estado-nación, que hiciera de la privacidad condición necesaria para el ejercicio de la tolerancia.

Existe un campo clave en el cual esta norma se ve tanto reforzada como cuestionada: la política lingüistica. La mayoría insiste en que todas las minorías aprendan y utilicen el lenguaje de la nación dominante, al menos en las transacciones públicas. Por su parte, las minorias, si son lo suficientemente importantes y especialmente si cuentan con una base territorial, querrán utilizar legítimamente su propia lengua en escuelas, documentos oficiales y públicos, etc. En ocasiones, alguna de las lenguas minoritarias es reconocida como lengua cooficial. Es más frecucnte, sin embargo, que la nación dominante vea transformada su propia lengua a causa de la utilización que de ella hacen las minorías (lo cual supongo que, de alguna manera, es asimismo un test de tolerencia).

Hay, pues, menos espacio para lo diferente en los Estados-nación que en los imperios multinacionales o los sistemas consociacionales. Puesto que los miembros (tolerados) de los grupos minoritarios son asimismo ciudadanos titulares de derechos y deberes, las prácticas grupales serán, por lo general, objeto de un mayor escrutinio de lo que lo eran en el seno de los imperios multinacionales. Aun así, existe una amplia gama de diferencias (en especial las 
religiosas) que han pervivido con éxito en el ámbito de los Estados-nación liberales y democráticos.

De hecho, a menudo, las minorias logran preservar bastante bien su cultura común, precisamente porque se hallan sometidas a la presión ejercida por la mayoría nacional. Los individuos pueden alejarse de su grupo, convertirse en miembros de la mayoría o ir asimilando lentamente el modo de vida mayoritario. Pero para la mayor parte de la gente estas autotransformaciones resultan en exceso difíciles o humillantes; por consiguiente, se aferran a sus propias identidades y a los hombres y mujeres que las comparten.

Las minorías nacionales son, por tanto, los grupos que probablemente corran un mayor riesgo. Si se hallan concentrados en un determinado territorio se harán sospechosos, quizás no sin razón, de desear crear un Estado propio o de querer incorporarse a un Estado vecino, en el que otros pueblos, con los que estan étnicamente relacionados, ostentan el poder soberano. En tiempos de guerra ( $y$ tanto si se hayan territorialmente concentrados como si no) será fácil que se cuestione su lealtad hacia el Estado-nación -incluso en contra de toda evidencia, tal y como ocurrió, por ejemplo, en el caso de los refugiados alemanes antinazis en Francia durante los primeros meses de la Segunda Guerra Mundial-. Nuevamente se puede decir que la tolerancia entra en crisis cuando las minorías parecen, o cuando los demagogos nacionalistas son capaces de hacerlas parecer, peligrosas. Otro ejemplo es el de la suerte que corricron los japonescs-americanos algunos años más tarde, momento en el cual, al parecer, sus compañeros estadounidense decidieron asumir el modelo de Estado-nación convencional. De hecho, los japoneses no eran (y siguen sin serlo) una minoría nacional en los Estados Unidos de América, al menos no se puede decir que fueran lo que tradicionalmente se entiende por una minoría: ¿cuál sería la mayoría nacional? Las mayorías nacionales estadounidenses lo son sólo con carácter temporal, se reagrupan de formas diversas según los objetivos perseguidos y según las ocasiones, mientras que precisamente uno de los rasgos esenciales del Estado-nación sería la existencia de una mayoría con carácter permanente. La tolerancia en el Estado-nación tiene una única fuente, se amplía o no, pero en una única dirección. En el caso de los Estados Unidos de América nos hallamos ante un modelo basado en una serie de acuerdos muy distintos.

El cuarto modelo de coexistencia y posible tolerancia seria el de la sociedad conformada por inmigrantes. En este caso, los miembros de los diferentes grupos han dejado atrás su base territorial, su patria, y llegan uno a uno, individualmente o en grupos familiares, a una nueva tierra en la cual se dispersan. Se agrupan, es cierto, en busca de consuelo, pero tan sólo forman grupos pequeños, siempre mezclándose con otros grupos similares existentes 
en ciudades, estados y regiones. Aquí no habria autonomia territorial posible (Quebec resulta una excepción crucial -como asimismo la constituyen los pueblos nativos conquistados-; querría, sin embargo, centrarme ahora básicamente en los inmigrantes). Si los grupos étnicos o religiosos desean pcrvivir, deben unirse en asociaciones voluntarias, lo que supone que el mayor peligro para su superviviencia puede provenir más de la indiferencia mostrada por parte de sus miembros que de la intolerancia de los demás. El Estado una vez liberado del lastre de los primeros inmigrantes (que, en todo caso, se veían a sí mismos creando un Estado-nación propio) no se encuentra comprometido con ninguno de los grupos que lo conforman. Como se suele decir, adopta una postura neutral frente a todos ellos, tolerando a todos, pero manteniendo de forma autónoma sus propios objetivos.

El Estado reclama para sí derechos jurisdiccionales exclusivos, considerando a sus ciudadanos como individuos, más que como miembros de un determinado grupo. Por lo tanto, en puridad, lo que resulta objeto de tolerancia son las elecciones y actividades individuales: actos de adhesión, participación en rituales o pertenencia a ciertos cultos, manifestaciones de diferencias culturales, etc. Se alienta así a los hombres y mujeres a tolerarse unos a otros en tanto que individuos y la diferencia se concibe, en cada caso, como una versión personalizada (y no estereotípica) de la cultura grupal. Esto supone, a su vez, que los miembros de cada uno de los grupos deben, si es que quieren ejercer la virtud de la tolerancia, aceptar los diferentes puntos de vista que cada uno plantea. Cada cual tiene que tolerar a todos los demás. No existe grupo alguno autorizado a organizarse coercitivamente, a asumir el control del espacio común - a monopolizar los recursos públicos. En principio, en las escuelas públicas se enseñan la historia, la ética o las normas cívicas imperantes en el Estado, ya que se entiende que éste no sólo constituye una identidad nacional, sino que posee, asimismo, una identidad política. La historia y cultura de los diferentes grupos o bien no se enseña en absoluto, o bien (como está ocurriendo últimamente en ciertas zonas de los Estados Unidos) se imparte en dosis cquivalentes, de forma «multicultural». Del mismo modo el Estado o bien no apoya a ninguno de los grupos, o bien promueve a todos por igual. Piénsese, por ejemplo, en los anuncios colocados en los transportes públicos durante los años cincuenta, a través de los cuales, con el fin de fomentar una especie de sentimiento religioso generalizado, se alentaba a los estadounidenses a asistir a la iglesia de su elección.

Como demuestra este último ejemplo, la neutralidad es una cuestión de grados. De hecho, algunos grupos se ven más favorecidos - en este caso aquellos grupos que cuentan con «iglesias»-. Pero, en todo caso, los demás siguen siendo tolerados. Ni la asistencia al culto ni ninguna otra práctica culturalmente específica se convierte en condición determinante de la ciudadanía. Por lo tanto, resulta relativamente sencillo, y en absoluto humillante, «escapar» del propio grupo y adoptar la identidad política general (se es «estadounidense»). 
Sin cmbargo, muchos miembros de una sociedad de inmigrantes prefieren adoptar una identidad compuesta o dual que les permita diferenciar entre diversas líneas político-culturales, por ejemplo, se adopta la identidad italo-americana. El guión que une los dos conceptos simboliza la aceptación de la «italianeidad» por parte de los demás estadounidenses, el reconocimiento de que ser «estadounidense» supone contar con una identidad política que no está ligada a pretensiones culturales fuertes o específicas. Evidentemente, la consecuencia que debemos extraer es que la (italiana» es una identidad cultural desvinculada de demandas de tipo político. Ésta es la única forma en que la «italianeidad» se tolera $y$, por lo tanto, debe perpetuarse a sí misma si puede, o mientras pueda, de forma privada, a través de los esfuerzos voluntarios y las contribuciones y compromisos asumidos por los italianos. En principio, esto es lo que ocurre no sólo en el caso de las minorías, sino con cualquier grupo rcligioso o cultural, si bien de nuevo hay que recalcar que no existen mayorías permanentes.

La pregunta sobre si los grupos pueden subsistir en estas condiciones, sin autonomía, sin acceso al poder estatal, sin reconocimiento oficial, sin base territorial y sin la necesidad de oponerse continuamente a una mayoría consolidada, aún no tiene respuesta. Por el momento, a las comunidades religiosas (tanto las sectarias como las que se organizan en torno a «iglesias») no lcs ha ido mal en los Estados Unidos. Pero es posible que una de las razones que expliquen este éxito relativo sea el considerable grado de intolerancia con el que muchas de ellas se han encontrado; factor, que, como ya he mencionado, en ocasiones produce efectos aglutinantes. El modelo de tolerancia característico de las sociedades de inmigrantes es un modelo emergente que aún no se puede considerar cerrado. Se podría pensar que esta forma de tolerancia (la de las elecciones individuales y las versiones personalizadas de cultura y religión) scría maximalista; de hecho, la forma más intensiva de tolerancia. $\mathrm{Y}$, sin embargo, no resulta en absoluto claro si este maximalismo tendrá como efecto, a largo plazo, el fomento o la disolución de la vida de grupo.

Es precisamente el miedo a que pronto los únicos objetos de tolcrancia sean individuos excéntricos lo que ha movido a algunos grupos (o a sus miembros mas comprometidos) a buscar un apoyo positivo por parte del Estado que podría concretarse, por ejemplo, en la percepción de subsidios o la adopción de un sistema de cuotas. Sin embargo, de acuerdo con la lógica del multiculturalismo, las ayudas estatales deben repartirse de forma igualitaria entre todos los grupos sociales. Si alguna vez se quisiera fomentar actuaciones públicas de este tipo habría que enfrentarse a decisiones dificiles de adoptar, puesto que, a tan amplia escala, resultaría imposible repartir de forma igualitaria cuotas y subsidios. Potencialmente, el alcance de la tolerancia es infinito, pero el Estado tan sólo puede sustentar la vida grupal en el marco de ciertos límites políticos y financieros. 
Permítanme resumir lo dicho hasta el momento analizando los cuatro tipos de regímenes y teniendo en cuenta, en primer lugar, las relaciones de poder que en cllos se crean y, posteriormente, el ámbito de las prácticas (moralmente problemáticas) que se toleran en su seno.

A menudo se afirma que la tolerancia entraña necesariamente una relación de desigualdad en la cual los grupos o individuos tolerados se sitúan en una posición inferior. Por lo tanto, deberíamos aspirar a algo mejor, a algo que vaya más allá de la tolerancia, como, por ejemplo, el respeto mutuo. Sin cmbargo, una vez descritos estos cuatro regímenes, la historia se complica bastante: el respeto mutuo no sería sino una de las formas que la tolerancia puede adoptar, quizás la más atractiva, pero no necesariamente la más estable.

En los imperios multinacionales, el poder reside en los burócratas de la organización central. Todo grupo incorporado al sistema es alentado a considerarse a sí mismo como tan carente de poder como los demás y, por lo tanto, incapaz de coaccionar o molestar a sus vecinos. Cualquier intento de coacción local se traducirá en una petición de ayuda al centro. Así, por ejemplo, griegos y turcos convivieron pacíficamente bajo el dominio otomano ¿Se respetaban mutuamente? Algunos, probablemente, otros no. Pero el tipo de relación que mantenían no dependía del respeto mutuo, sino de la sujeción común. Por el contrario, en el caso de la consociación sí se requiere un respeto mutuo, al menos entre los líderes de los diversos grupos, ya que éstos no sólo deben coexistir, sino que, además, se ven forzados a negociar entre ellos los términos que van a presidir esa coexistencia. Chipre, con anterioridad a su partición en un Estado turco y otro griego, representa un buen ejemplo fallido.

En los Estados-nación el poder reside en la mayoría nacional, que, como hemos visto, lo utiliza para lograr sus propios objetivos. Esto no implica necesariamente la creación de barreras a la mutualidad entre individuos. De hecho en los Estados democráticos es muy probable que tal mutualidad florezca. Pcro los grupos minoritarios se hallan en situación de inferioridad a causa de su menor número y serán democráticamente derrotados en la mayoría de los temas relacionados con la cultura pública. Un problema similar se da al constituirse una sociedad de inmigrantes, cuando los primeros en llegar aspiran a convertirse en ciudadanos nacionales. A través de las sucesivas oleadas de inmigración se crea lo que podría considerarse nuevamente (al menos en principio) un Estado neutral, la versión democrática de la burocracia imperial. Pero este Estado busca como interlocutor a los individuos más que a los grupos, generándose así una sociedad abierta en la que se exige a todos que toleren a todos los demás. Presumiblemente será posible en la actualidad avanzar en la tan preconizada dirección del «más allá de la tolerancia». No obstante, 
como he puesto de manifiesto, sigue sin estar claro cuánta diferencia grupal quedará por respetar una vez que nos movamos en esa dirección.

\section{VII}

Sin duda, la forma más abicrta de ejercer la tolerancia se da en un caso no contemplado hasta aquí: el de la sociedad internacional, en el seno de la cual no se permite a nadie decidir si tolera o no a tal o cual grupo o práctica. La legislación internacional legitima la «intervención humanitaria» por parte de cualquier Estado capaz de llevarla a cabo en casos de masacre, persecución radical o deportaciones en masa. Supongo, pues, que se puede decir que, al menos en principio, estas prácticas no se toleran. Cicrtamente, cuando se da una intervención real (relativamente rara en la historia de los Estados) se puede decir que no se toleran de hecho. Pero, con caracter general, los agentes de la sociedad internacional (líderes políticos y diplomáticos) y tal vez también los pucblos a los que dicen representar resultan ser notoriamente tolerantes respecto de lo que ocurre más allá de sus fronteras. Se muestran resignados, indiferentes, curiosos o entusiastas (poco importa en realidad) y se sienten poco inclinados a intervenir. Evidentemente, también puede darse el caso de que se muestren hostiles respecto de la cultura y costumbres de sus vecinos, pero, dadas las condiciones establecidas por la sociedad internacional, no estén preparados para pagar los costes que tendría la interferencia. O también es posible que, siendo culturalmente intolerantes, acepten la lógica de la soberanía que comporta un cierto tipo de tolerancia institucional.

De entre todos los regímenes políticos de los que me he ocupado directamente, el que más ccrca está de guiarse por una lógica similar es el imperio multinacional. Las comunidades autónomas cuentan con leyes y sistemas legales diferentes y, a menos que sus miembros interactúen con los miembros de otras comunidades (a través del comercio por ejemplo), con alta probabilidad se les permitirá reforzar sus propias comprensiones compartidas de lo que debe entenderse por un comportamiento acorde con la legalidad. En los mercados comunes no se tolerarán costumbres comerciales extrañas, pero no se darán muchas interferencias en la labor de los tribunales locales que resuelven, digamos, asuntos internos.

Considérese, por ejemplo, la extraordinaria tenuencia con la que, en 1829 , finalmente, los británicos abolieron el suitee (la autoinmolación de las viudas hindúes en la pira funeraria del marido) en sus colonias. Durante largos años, la East India Company, primero, y el gobierno británico, después, toleraron esta práctica basándose en 10 que un historiador del siglo $\mathrm{xx}$ describe como «su intención explícita de respetar tanto las creencias hindúes como las musulmanas y de permitir el libre ejercicio de los derechos religiosos\%. (Autores anteriores hubieran hablado de «ritos», lo que, posiblemente, tuviera más sen- 
tido.) Incluso gobernantes musulmanes que, según este mismo historiador, no respetaban en modo alguno las creencias hindúes, tan sólo realizaron esfuerzos espotádicos y poco convincentes por suprimir esta práctica. La tolerancia imperial abarca, por lo tanto, incluso el suttee, lo cual, teniendo en cuenta las descripciones británicas de lo que esta práctica realmente suponía, es llegar muy lejos.

Resulta al menos concebible que en el ámbito de los pactos consociacionales, pudicra darse un grado de tolerancia similar, siempre que el poder ejercido por las comunidades unidas estuviera más o menos equilibrado y los líderes de alguna de ellas mostraran un firme compromiso en relación con alguna práctica consuetudinaria. Sin embargo, en el seno del Estado-nación, por definición, no se da cste equilibrio de poder y, por tanto, no se toleraría que minorias religiosas o nacionales practicaran costumbres como el suttee. Tampoco resulta probable que un tipo de tolerancia de tan largo alcance se diera en el seno de una sociedad de inmigrantes, donde cada uno de los grupos es una minoría en relación con los demás. Del caso de los mormones en los Estados Unidos de América se puede inferir que no se tolerarán prácticas desviadas de la legislación común, ni siquiera cuando tan sólo se pretenda regular asuntos internos que únicamente podrían afectar a la vida de la comunidad minoritaria en sí. En estos dos últimos casos, el Estado, a través de la ciudadanía, garantiza la igualdad a todos sus miembros e impone una legislación homogénea. No existen tribunales comunales; todo el país es una jurisdicción única en la que, siempre que esté en su mano, las autoridades estatales se ven obligadas a, digamos, impedir la celebración de un suttee, del mismo modo que deben abortar un intento de suicidio. $Y$ en el caso de que, como ocurría a menudo, el suttee se intentara llevar a acabo por la fuerza, deben considerar esta coacción como un asesinato, sin que pueda mediar excusa religiosa o cultural alguna.

En otros casos que no suponen un reto directo para los valores morales de la comunidad más numerosa (la mayoría nacional o la coalición de minorías) pueden aceptarse excusas de tipo religioso o cultural y es posible que se toleren prácticas fucra de lo comúnmente aceptado, tal vez incluso ilegales. Esto sucede respecto de minorías organizadas en sectas, como los amish estadounidenses o los hasidim, a los que en ocasiones las autoridades estatales ofrecen (a veces a través de la mediación de los tribunales de justicia) soluciones de compromiso. Sin embargo, no se ofrecen concesiones similares a grupos mayores o más poderosos y siempre existe la posibilidad de que cualquier miembro de la secta ponga en cuestión los acuerdos vigentes alegando sus derechos como ciudadano. Imaginemos que se llega a un compromiso por el cual se autoriza a las niñas musulmanas a utilizar el velo tradicional en las escuelas públicas francesas. (Lo que impide un acuerdo de este tipo es el hecho de que los musulmanes en Francia no constituyen una pequeña minoría, pero dejemos eso de lado en este ejemplo.) Sería necesario casar este compromiso con las 
tradiciones laicas de la educación francesa que, por lo demás, seguirían imperando en el ámbito del calendario escolar o la confección de los planes de estudio. Supongamos que, en algún momento, cierto número de chicas musulmanas afirman que son obligadas por sus familias a llevar el velo, y que el acuerdo alcanzado respalda esta coacción. Tal vez en este caso fuera necesario renegociar el acuerdo. En el Estado-nación y en la sociedad de inmigrantes (aunque no en el imperio multinacional), el derecho a ser protegido frente a coacciones de este tipo tendría prioridad sobre los valores defendidos por la religión o cultura minoritarias.

\section{VIII}

He hablado de algunos de los límites impuestos a la tolerancia, pero aún no he dicho nada sobre los regímenes intolerantes que es lo que actualmente son, de hecho, muchos imperios y Estados-nación. En algunos casos consiguen climinar la diferencia, pero en otros, cuando utilizan métodos como el genocidio, las deportaciones en masa o la «limpieza étnica», en realidad se produce un reforzamiento de lo diferente. Se identifica a los miembros de grupos minoritarios, se les persigue a causa de su pertenencia a estos grupos, se les obliga a confiar los unos en los otros, a fraguar estrechas solidaridades.

Aun así, ni los líderes de estos grupos ni sus miembros más devotos optarían por un régimen de intolerancia. Por lo general, si tuvieran la oportunidad buscarian algun tipo de tolerancia individual o colectiva: su asimilación con el cuerpo de ciudadanos o el reconocimiento de su status en la sociedad interna o internacional que comportaría la existencia de un cierto grado de autonomía de gobierno, consociacionismo o estatalidad soberana.

Por tanto, podría hablarse de dos proyectos centrales de la política democrática moderna. Normalmente se les concibe en términos de exclusión mutua: o son los individuos o son los grupos los que se ven libres de persecución y rescatados de la invisibilidad - y en el primero de los casos, el de los individuos, sólo en la medida en que abandonan sus grupos de referencia-. Véase la descripción que Jean Paul Sartre hace del punto de vista típicamente democrático de la cucstión judía: "Se desea separar al judío de su religión, de su familia, de su comunidad étnica, para sumergirle en el crisol democrático del que emergerá desnudo y solo, una partícula individual y solitaria igual al resto de las partículas.» (Obviamente este proyecto puede describirse de un modo más positivo; puesto que no es ése mi objetivo aquí, creo innecesario ahondar más en ello.) Como alternativa existe la posibilidad de dotar al grupo como un todo de voz y atribuirle un lugar y una política propias. Mucha gente que se consideraba políticamente de izquierdas creía que esto requeriría de un esfuerzo por lograr la integración, según el modelo seguido por la clase obrera y los movimientos socialistas; tomar al asalto y quebrar las murallas de la 
ciudadela burguesa. Pero lo que los grupos de los que me ocupo aqui deben librar es una batalla en pro de la creación de vínculos y fronteras. El eslogan fundamental de esta lucha debe ser «autodeterminación», lo que implica la necesidad de reivindicar un territorio $o$, al menos, la creación de una serie de instituciones independientes y, por tanto, descentralización, delegación de poderes, autonomía, partición, soberanía. Crear los límites adecuados no sólo en sentido geográfico, sino también en términos funcionales, es tremendamente complicado, pero nccesario, si los grupos han de ejercer un control efectivo sobre sus propias vidas $\mathrm{y}$, además, lo han de hacer con alguna seguridad.

Esta tarea se sigue realizando hoy en día, adaptando los antiguos acuerdos do la época imperial, extendiendo el moderno sistema internacional, haciendo proliferar los Estados-nación, el número de regiones que cuentan con instituciones de autogobierno, potenciando las autoridades locales, etc. Observemos lo que se reconoce y tolera en todos estos casos: se trata siempre de grupos y sus micmbros, hombres y mujeres con identidades singulares o primarias, de tipo étnico o religioso. Obviamente, el éxito de esta tarea depende de la movilización de estas gentes pero, en realidad, tan sólo son sus líderes los que entablan relación unos con otros, los que cruzan los límites de uno en uno (excepto cuando el acuerdo es de naturaleza militar). La autonomía confirma la autoridad de las ćlites locales tradicionales. La consociación es una especie de acuerdo sobre el reparto del poder entre estas mismas élites; los Estados-nación interactúan a través de sus cuerpos diplomáticos y sus líderes políticos. Para el grueso de los miembros del grupo, la tolerancia se manticne por la vía de la separación, sobre la base de la asunción de que estas gentes se conciben a sí mismas en tanto que miembros del grupo y, prioritariamente, desean asociarse entre sí. «Las buenas fronteras hacen buenos vecinos» («good fences make good neighbors").

Sin embargo, a través del último de mis modelos de tolerancia se sugiere un esquema distinto $y$, tal vez, un proyecto posmoderno. En las socicdades de inmigrantes (así como en aquellos Estados-nación sometidos a la presión de la recepción de inmigrantes), la gente experimenta lo que podría pensarse que es una vida exenta de compromisos, en la que no se dan identidades fïmes o singulares. Se podría afirmar que la diferencia se dispersa, de modo que puede ser hallada todos los días y en cualquier lugar. Los individuos se mezclan, pero no adoptan necesariamente una identidad común. La influencia ejercida por los grupos sobre sus miembros es más laxa que nunca, si bien en ningún caso se puede decir que desaparezca por completo. El resultado es el surgimiento continuo de individuos ambiguamente identificados, que contraen matrimonio entre sí, y, por tanto, lo que se da es literalmente multiculturalismo, que se concreta no sólo en la socicdad globalmente considerada, sino asimismo en todas y cada una de las familias, incluso en todos y cada uno de los individuos. Por tanto, aquî la tolerancia empieza en casa, donde, a menudo, debemos llegar a acuerdos de tipo étnico, religioso y cultural con 
nuestras esposas, familia política e hijos - así como con nuestras propias identidades compuestas o divididas-. En parte, el fundamentalismo religioso debe ser entendido como el rechazo de una paz de este tipo, como un ataque a la ambigüedad.

El más destacado defensor teórico de este proyecto posmoderno ha sido la escritora franco-búlgara Julie Kristeva. Ella nos urge a reconocer este mundo de extraños, así como a tomar conciencia del extraño que existe en nosotros mismos. Además de este argumento psicológico, en el que no puedo entrar en este momento, ella se remite a un argumento moral muy antiguo, cuya primera versión bien pudiera ser el mandato bíblico: no oprimirás al extranjero, puesto que tú también fuiste extranjero en la tierra de Egipto. A efceto de poder reiterarlo en el mundo contemporáneo, Kristeva altera el tiempo verbal y la localización geográfica: no oprimáis al extranjero, porque vosotros sois extranjeros en esta misma tierra. Sin duda debe resultar más sencillo tolerar la "otredad" si tomamos conciencia del otro en nosotros mismos. Pongo en duda, sin embargo, de que esta mera toma de conciencia sea suficiente por sí misma, de un modo estrictamente moral. No vivimos todo el tiempo en un mundo de extraños, tampoco nos enfrentamos a la ajenidad de los demás de forma individual, uno a uno, sino también colectivamente, en situaciones en las que la moralidad debe ser secundada por la política.

No se trata de que el proyecto posmoderno simplemente reemplace al moderno, como ocurriría, por ejemplo, en alguna gran metanarrativa sobre las etapas históricas. Lo uno se solapa con lo otro, sin eliminarlo en modo alguno. Siguen existiendo límites, pero éstos se vuelven imprecisos debido a las intersecciones. Sabemos que nosotros somos esto a aquello, pero este conocimiento es incierto, porque también somos esto $y$ aquello. Existen grupos de identidad fuertes que hacen valer sus derechos políticamente, pero la lealtad de sus miembros se mide por grados a lo largo de un amplio continuum, siendo así que cada vez existe un número mayor de personas que se agrupan en el extremo más alejado (ésta sería la razón por la que los militantes situados cn el extremo más cercano manifestarian sus protestas de una forma tan fuerte hoy día).

La existencia de este dualismo entre lo moderno y lo posmoderno requiere de una doble reconciliación de la diferencia; en un primer momento hay que atender a las vertientes individuales, singulares y colectivas, para pasar a centrarse posteriormente en la vertiente pluralista, dispersa o dividida (también es posible alterar este orden; no quiero defender un argumento secuencial, si bien es más probable que se dé el orden que acabo de exponer). Necesitamos ser tolerados y protegidos, tanto como ciudadanos y miembros de un grupo como también en la medida en que somos extraños. La autodeterminación debe ser tanto política como personal -ambas se hallan interrelacionadas, pero no son lo mismo- La antigua forma de entender la diferencia, que mantenía a los individuos unidos a sus grupos, autónomos o soberanos, no 
será aceptada por individuos disidentes o ambivalentes. Pero cualquier forma de comprensión nueva, exclusivamente centrada en los disidentes, será rechazada por los hombres y mujeres que luchan por establecer, elaborar, revisar y hacer valer una tradición religiosa o cultural común. Por tanto, la diferencia debe ser doblemente tolerada, cualquiera que sea la mezcla de resignación, indiferencia, curiosidad o entusiasmo que se suscite (no es preciso que en todos los casos esta mezcla sea idéntica).

Incluso aquellos de nosotros que nos consideramos entusiastas de la diferencia tenemos el compromiso de luchar contra aquellas diferencias, culturales y personales, que nos causan dificultades. Porque no queremos tolerar el odio y la crueldad, y nuestro respeto hacia lo diferente tampoco se extiende hasta englobar prácticas grupales opresivas (que sí eran regularmente toleradas por los burócratas imperiales). Cuanto más estrecha es la unión en la que vivimos, los límites de la tolerancia se convierten en mayor medida en problemas cotidianos. Y uno de los objetivos del proyecto posmoderno sería el garantizar la viabilidad de unos vínculos más estrechos. Así pues, las líneas continuas de los antiguos mapas culturales y políticos se han convertido en líneas difusas, discontinuas, pero, no obstante, la convivencia a lo largo y ancho de estas líneas sigue constituyendo un problema. 


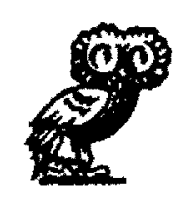

Revista de Occidente

Septiembre 1996

N. ${ }^{\circ} 184$

\section{HOMENAJE A JULIO CARO BAROJA}

Coordinación de Rogelio Rubio

Artículos de

Carmen Caro,

Pío Caro Jaureguialzo,

Manuel Gutiérrez Estévez,

Jon Juaristi,

Antonio Morales Moya,

Bernabé Sarabia

Un diálogo epistolar entre

José Ortega y Gasset y Julio Caro Baroja presentado por

Soledad Ortega 